\title{
SCI, SCIE, SCIEN...
}

Beom Sun Chung, Min Suk Chung

Department of Anatomy, Ajou University School of Medicine, Suwon, Korea

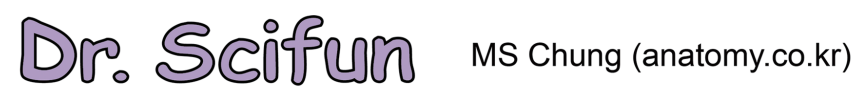

SCI, SCIE, SCIEN..
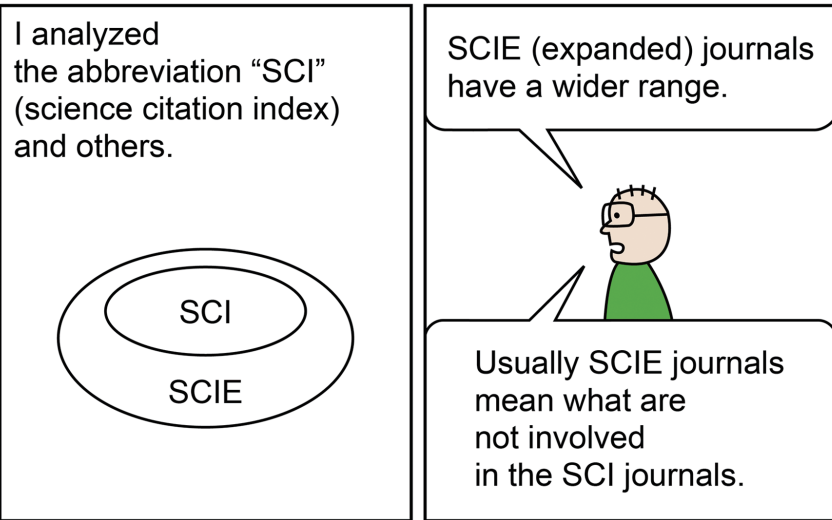

Received: July 14, 2017

Accepted: August 4, 2017

Correspondence to Min Suk Chung dissect@ajou.ac.kr

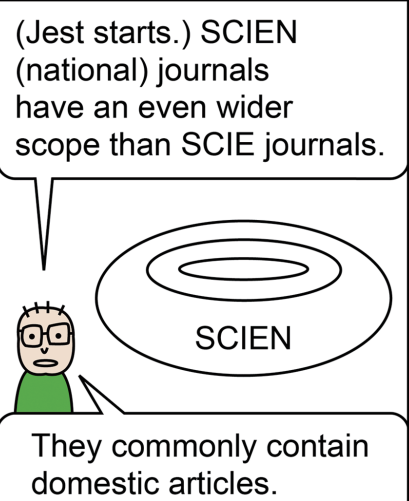

(Jest starts.) SCIEN (national) journals have an even wider scope than SCIE journals. domestic articles.

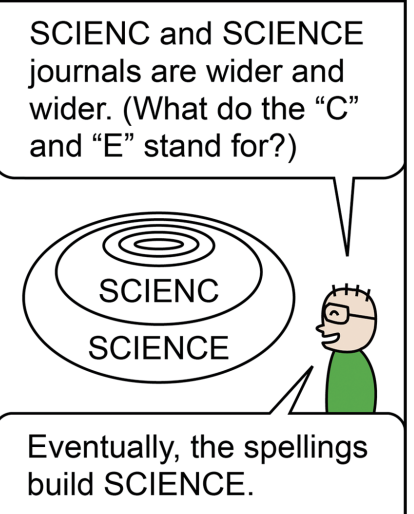

Thomson Reuters made the words SCI and SCIE. The words do not stand for SCIENCE, but they serve as good materials for the cartoon. I didn't miss this opportunity, and drew this episode like animals that didn’t miss the prey. 


\section{(D)}

Stars on white coats

\section{Issue was the white coats} in laboratory.

Our coats are similar, so it is confusing.

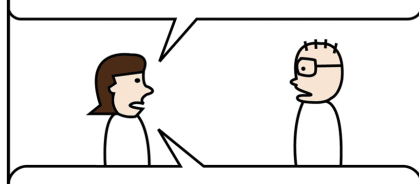

My suggestion is that we use hierarchical military ranks.

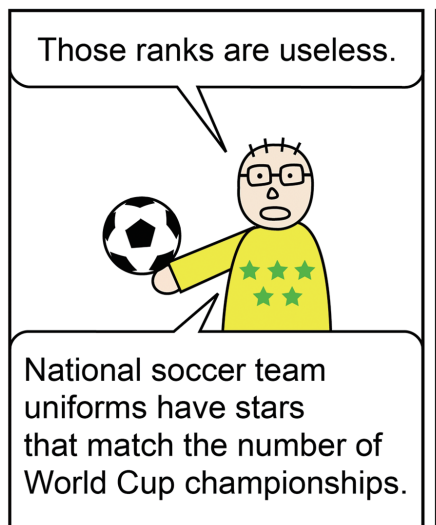

Master's students are like soldiers, while PhD students are like company officers,

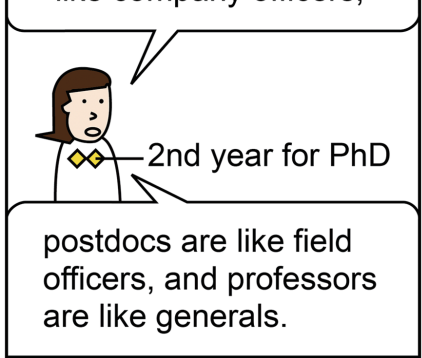

We should put stars according to how many $\mathrm{SCl}$ articles we have published as the first or corresponding author.

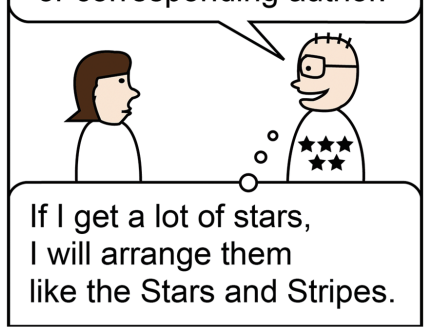

We should forget about the hierarchy among the lab members. For example, master's students can write better articles than $\mathrm{PhD}$ students. Ability and passion are more important than ranking. Note that forgetting about hierarchy doesn't mean having fist fights.

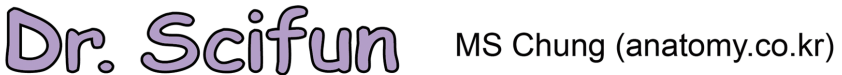

\section{One's satisfaction, other's approval}

I think about

one's satisfaction

and others' approval.

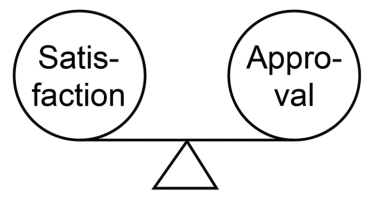

There could be research that satisfies a scientist, but others don't approve it.

On the contrary, others might approve the research that doesn't satisfy the scientist.

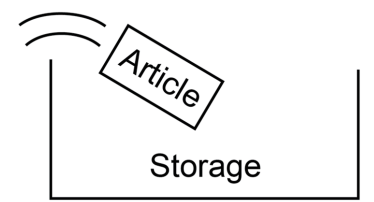

For example, there is no pride in the article.
For example, there is no article published in the journal.

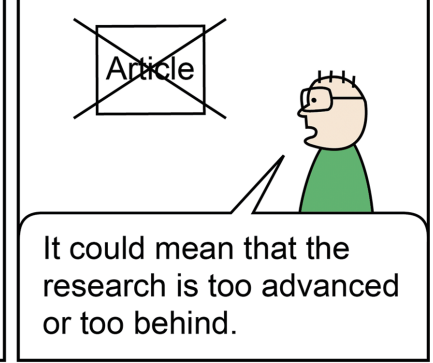

It is because the author follows the research fad by reading others' faces.

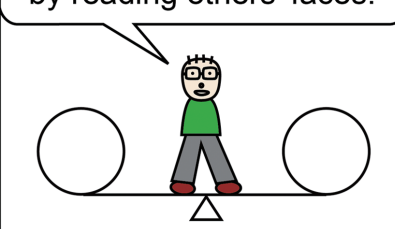

Scientist should compromise for others' approval, but be stubborn for satisfying oneself.
Other's approval is required prior to one's own satisfaction. At first, when scientists get jobs or promotion, they check their articles for other's approval. However, after securing the job, they check their life-time achievements for self-satisfaction. The process is like the lives of artists. 
Drose

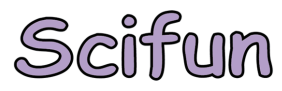

MS Chung (anatomy.co.kr)

Hopeful, disappointed
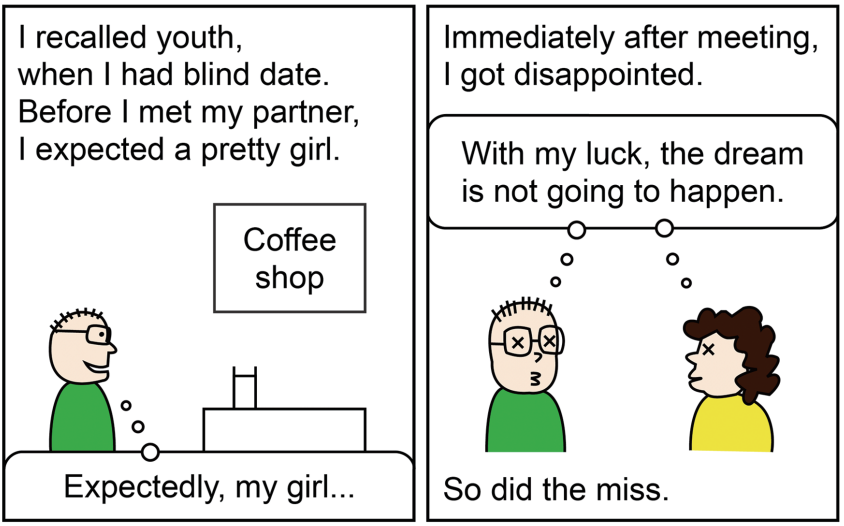

I became a scientist. Before publishing my manuscript, I am hopeful.
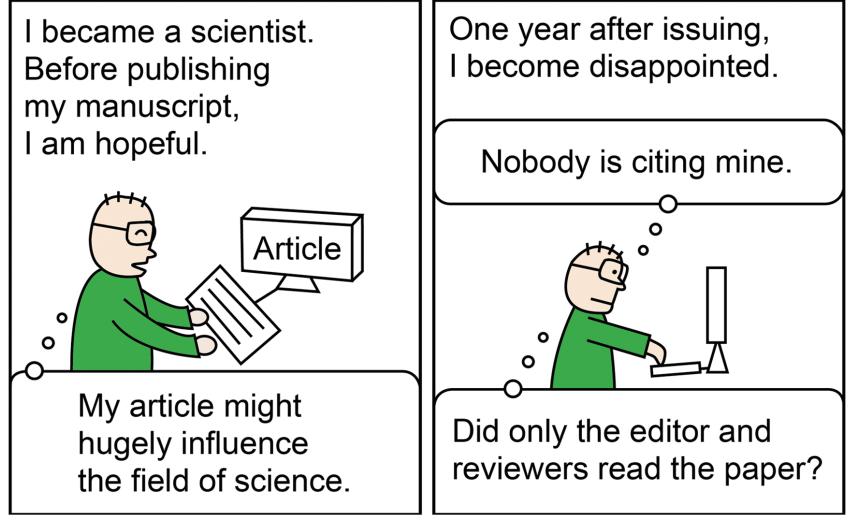

Experienced scientists know that "by any chance" can be changed to "expectably." However, they think only about "by any chance" rather than "expectably." Then, they have hope and work hard. Thinking about "by any chance" and deceiving themselves can be the basic driving force of science research.

These cartoons were published in the authors' homepage (anatomy.co.kr).

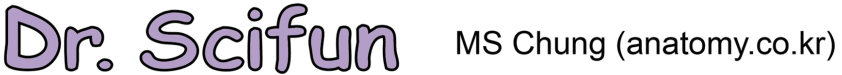

Experiment thief, article thief
In Korea,

rice thief represents

the delicious side dish.

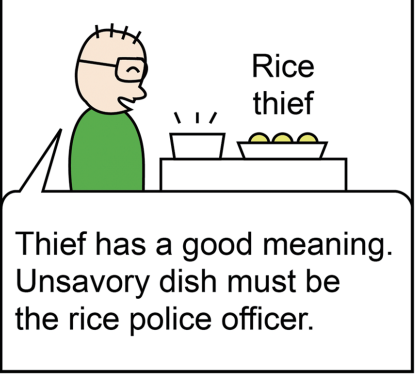

A sincere scientist can have the nickname, article thief.
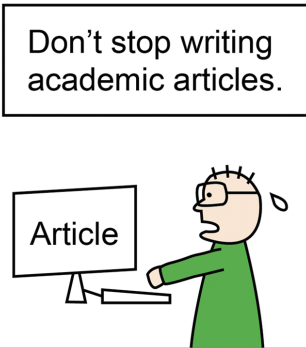

A diligent graduate student may be called the experiment thief.

\section{Don't}

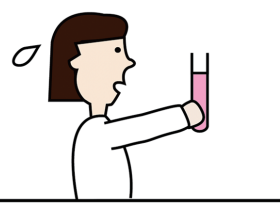

Lazy one become the experiment police and article police.

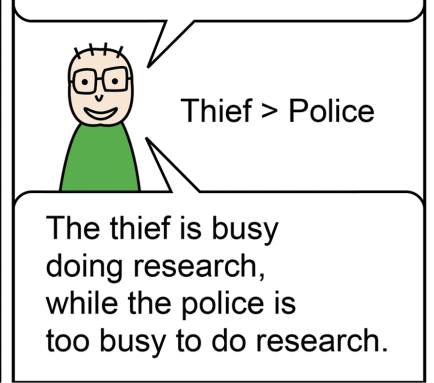

delay experiment.

Graduate students and scientists are the ones who are expected to put their top priority on conducting experiments and writing scientific articles. This commitment would keep them busy and eventually rewarded. However, many of them are occupied by other things, and put aside their researches. Here lies the problem.

\section{Conflict of Interest}

No potential conflict of interest relevant to this article was reported. 